\title{
Incidence of tuberculosis in children on antiretroviral therapy: a retrospective cohort study
}

\author{
Aklilu Endalamaw*, Eshetu Hailesilassie Engeda and Nega Tezera
}

\begin{abstract}
Objectives: Be aware of the burden of tuberculosis among high-risk population is important. Three hundred fiftytwo children were participated in this study. Survival analysis was conducted. We assessed the incidence of tuberculosis and its predictors in children on ART.

Results: Tuberculosis incidence rate in children on ART was 2.63 per 100 person-years. Those children who were on baseline World Health Organization clinical stages 3 and 4 (AHR (adjusted hazard ratio) =3.0; 95\% Cl 1.2-7.7), "fair" and "poor" ART adherence (AHR $=4.0 ; 95 \% \mathrm{Cl} 1.5-10.8$ ), late initiation of ART ( $A H R=4.0 ; 95 \% \mathrm{Cl} 1.5-10.6$ ), and less than 6 months duration on ART (AHR $=5.5 ; 95 \% \mathrm{Cl} 1.5-20.6)$ were more likely to develop tuberculosis infection. The incidence rate of TB in children on ART was high. This study suggests a need to give attention to advanced AIDS stages and improve timely initiation of ART and level of adherence to ART.
\end{abstract}

Keywords: Antiretroviral therapy, Children, HIV, Tuberculosis, Ethiopia

\section{Introduction}

Tuberculosis (TB) is one of the common causes of morbidity and mortality among human immunodeficiency virus positive patients (HIV) [1, 2], particularly in children $[3,4]$. It is also listed among the top ten causes of death worldwide, in which one-third of all deaths of Acquired Immunodeficiency Syndrome (AIDS) are related to TB $[5,6]$.

According to 2016 World Health Organization (WHO) report [5], 10\% of TB cases were children and people living with HIV. In Ethiopia, around 16,000 TB cases were found in HIV positive patients [7].

According to Sustainable Development Goal, there is a plan to reduce $80 \%$ of TB incidence by 2030 . The "End TB" strategy has also set to stop TB epidemic through a process of reducing the number of TB deaths per year, TB incidence rate per year, and the catastrophic TB costs [8]. Initiation of antiretroviral therapy (ART) [9-14],

\footnotetext{
*Correspondence: yaklilu12@gmail.com

Department of Pediatrics and Child Health Nursing, School of Nursing, College of Medicine and Health Sciences, University of Gondar, P.O.BOX 196, Gondar, Ethiopia
}

cotrimoxazole prophylaxis therapy (CPT) [15], isoniazid prophylaxis therapy (IPT) [16-18], chemotherapy, tuberculosis vaccine, and early diagnosis [19] are help to prevent active TB infection in children.

Despite different interventions, TB incidence rate in children on ART is high in different settings at different time. Notably, 0.28 per 100 person-years reported in Latin America [16], 0.83 in China [20], 4.0 in South Africa [21], and 17.4 in East Africa [22].

Delayed motor development, underweight, WHO clinical stage 3 or 4 [23], CD4 (Cluster of Differentiation 4) cell count below threshold, anemia [24], and virological failure [25] are some of the contributing factors of TB incidence identified from previous studies.

In Ethiopia, information about the burden of new infection of TB in different settings is required [26]. This study can be used as an input to see the performance of activities implementing at district level based on 2030 end TB strategy progress evaluation. Besides, it helps to clinician to incorporate different predictors of active TB infection in HIV care clinic to the better prevention of the disease. Therefore, tracing TB among high-risk 
groups, like children on ART is important. This study was assessed the incidence of TB and its predictors in children on ART.

\section{Main text \\ Methods \\ Study design, period, setting, and population}

A retrospective cohort study from March 2005 to April 2017 was conducted at Debre-Markos Referral Hospital, northwest Ethiopia. Debre-Markos town is found in northwest Ethiopia $299 \mathrm{~km}$ from the capital Addis Ababa. According to the 2007 national census, this town has a total population of 62,497 [27]. It has one referral hospital, which serves more than 3.5 million people in its catchment area, where HIV care services have been provided since 2003. FMOH's 2007 pediatric HIV/AIDS care guideline [28] was revised in 2015. Accordingly, regardless of the WHO clinical stage or CD4 cell count, all HIV positive children had started HAART since 2015.

All HIV positive children on ART were the study population. During the study period, 563 children were enrolled to ART Clinic. Of these, 352 children were included in this study.

Those children who had at least 1-month follow-up at the ART clinic were included. Children who were diagnosed to TB and those started anti-TB treatment at the beginning of the follow-up were excluded.

\section{Operational definitions}

Events TB cases were identified based on TB diagnosis guideline of the Ethiopian Ministry of Health [28], using sputum or gastric aspirate microscopy, chest X-ray examination, and/or histopathology.

Censored Lost, drop out, transfer out, died of other causes or completed study period before developing TB.

TB-free probability time Considered between ART starting and TB diagnosis date.

Level of ART adherence Good $(\geq 95 \%$ or $<2$ doses missed per month or $<3$ dose missed per 2 months), fair (85-94\% or 3-5 doses missed per 30 doses or 3-9 doses of 60 doses), and poor (less than $85 \%$ or $>6$ doses of 30 doses or $>9$ dose of 60 doses) [29].

Underweight According to WHO curve, weight for age $\mathrm{Z}$ score $<-2$ standard deviation.
CD4 cell count below threshold CD4 cell count $<1500 /$ $\mathrm{mm}^{3}(<25 \%)$ for $<12$ months, CD4 cell count $<750 / \mathrm{mm}^{3}$ $(<20 \%)$ for age $12-35$ months, CD4 cell count $<350 /$ $\mathrm{mm}^{3}(<15 \%)$ for age 36-59 months, and CD4 cell count $<200 / \mathrm{mm}^{3}(<15 \%)$ for age $\geq 60$ months [30].

\section{Data collection tools, procedures, and quality control}

Data were collected using the data abstraction tool prepared from WHO ART follow-up chart. The medical record numbers of HIV-positive children who started ART were taken from computer records. Then, charts were drawn from the patients' medical chart room. Three clinical nurses who took ART training were collected the data. The overall activities and the aim of the study were informed to data collectors. Questions raised by data collectors were explained to create better understanding. The principal investigator and one supervisor followed data collection process. Consistency of data was checked by random selection of five percent of the extracted data tool to cross-check with the medical charts of children. Each chart was coded to avoid the duplication of data.

\section{Data processing and analysis}

Data was entered into EPI data 3.1 and exported to STATA version 12 statistical package software for analysis. Summary statistics were applied to describe the study population in relation to studied variables. TB incidence rate was determined per 100 person-years.

Kaplan-Meier survival function was used to estimate TB-free probability. Those variables had reported p-value $<0.2$ in the log-rank test were entered into the multivariable Cox-proportional model. The Cox-proportional hazards model assumption was checked for variables in the final model by the Schoenfeld residual test. None of variables broke the proportional assumption model. An adjusted hazard ratio with a $95 \%$ confidence interval (CI) was estimated. Those variable had p-value below 0.05 in the multivariable analysis was considered statistically significant predictors of TB infection.

\section{Ethical considerations}

The School of Nursing on behalf of the University of Gondar Institutional Ethical Review Board issued the ethical clearance. A written permission was obtained from the administrative office of Debre-Markos Referral Hospital and wrote a letter of permission to ART focal person. The names and/or identification numbers 
of patients were not recorded on the data extraction tool. All data were kept strictly confidential and used only for the study purposes.

\section{Results}

Demographic, clinical, laboratory, and medication-related characteristics

Three hundred fifty-two HIV positive children on ART were included in this study. The mean age of the study participants was 6.73 (standard deviation $=3.84$ ) years. Majority $(43.7 \%)$ of them were found in the age group of 5-10 years. Slightly more than half $(50.9 \%)$ of the children were male and nearly $90 \%$ from urban area. For more than two-thirds (70.5\%) of children's parents were both alive. Majority $(78.1 \%)$ of children were on WHO clinical stage 1 and 2. 80.4\% had above threshold CD4 cell count. About $14.2 \%$ had $<10 \mathrm{mg} / \mathrm{dl}$ hemoglobin level, $22.3 \%$ were underweight, $94.0 \%$, and $31.2 \%$ of children were taking CPT and IPT, respectively. Majority (82.4\%) of children were initiated ART lately. Children who had good adherence level to ART and on ART for greater than 6 months were $85.5 \%$ and $84.1 \%$, respectively (Table 1 ).

\section{Tuberculosis incidence rate during follow-up}

A follow-up was conducted from 1 to 143 months on 352 participants yielded 1294.7 years-time at risk. New TB cases were observed in 34 (9.7\%) of study participants making the overall TB incidence rate $2.63(95 \%$ CI 1.9-3.7) per 100 person-years.

\section{Kaplan-Meier TB-free probability}

The median TB-free probability time was 135 months. TB-free probability by the end of the follow-up was 0.82 (95\% CI 0.76-0.87) (Fig. 1).

\section{Predictors of TB incidence in HIV positive children on ART}

In the multivariable Cox-regression, WHO clinical stage, initiation time of ART, level of adherence to ART, and duration on ART were significant predictors of TB incidence.

Children on WHO clinical stages 3 and 4 were 3 times $(\mathrm{AHR}=3.0,95 \% \mathrm{CI} 1.2-7.7)$ more risk of getting $\mathrm{TB}$ infection than those on WHO clinical stages 1 and 2 . "Fair" and "poor" adherence level to ART was 4 times $(\mathrm{AHR}=4.0$, 95\% CI 1.5-10.8) more risk of developing TB compared to "good" ART adherence. Late initiation of ART was 4 times (AHR $=4.0,95 \%$ CI 1.5-10.6) higher risk of developing $\mathrm{TB}$ than starting otherwise. Children who took ART for less than or equal to 6 months were
Table 1 Baseline demographic, clinical, laboratory and medication-related characteristics of children on ART at Debre-Markos Referral Hospital, Northwest Ethiopia from March 2005 to April $2017(n=352)$

\begin{tabular}{|c|c|c|c|}
\hline Characteristics & Categories & Frequency & Percent (\%) \\
\hline \multirow[t]{3}{*}{ Age } & $0-5$ year & 140 & 39.8 \\
\hline & $5-10$ year & 154 & 43.7 \\
\hline & 10-15 year & 58 & 16.5 \\
\hline \multirow[t]{2}{*}{ Sex } & Male & 179 & 50.9 \\
\hline & Female & 173 & 49.1 \\
\hline \multirow[t]{2}{*}{ Residence } & Urban & 313 & 88.9 \\
\hline & Rural & 39 & 11.1 \\
\hline \multirow[t]{3}{*}{ Parent status } & Both parents alive & 248 & 70.5 \\
\hline & $\begin{array}{l}\text { Paternal and mater- } \\
\text { nal orphan }\end{array}$ & 80 & 22.7 \\
\hline & Double orphan & 24 & 6.8 \\
\hline \multirow[t]{2}{*}{ WHO clinical stage } & Stage 1 and 2 & 275 & 78.1 \\
\hline & Stage 3 and 4 & 77 & 21.9 \\
\hline \multirow[t]{2}{*}{ CD4 count } & Below threshold & 69 & 19.6 \\
\hline & Above threshold & 283 & 80.4 \\
\hline \multirow[t]{2}{*}{ Hemoglobin level } & $<10 \mathrm{mg} / \mathrm{dl}$ & 50 & 14.2 \\
\hline & $\geq 10 \mathrm{mg} / \mathrm{dl}$ & 302 & 85.8 \\
\hline \multirow[t]{2}{*}{ Nutritional status } & Underweight & 82 & 22.3 \\
\hline & Normal & 270 & 76.7 \\
\hline \multirow{2}{*}{$\begin{array}{l}\text { Ever taking cotrimox- } \\
\text { azole preventive } \\
\text { therapy }\end{array}$} & Yes & 331 & 94.0 \\
\hline & No & 21 & 6.0 \\
\hline \multirow{2}{*}{$\begin{array}{l}\text { Ever taking isoniazid } \\
\text { prophylaxis therapy }\end{array}$} & Yes & 110 & 31.2 \\
\hline & No & 242 & 68.8 \\
\hline \multirow{2}{*}{$\begin{array}{c}\text { Months on care } \\
\text { before ART }\end{array}$} & $\leq 3$ month & 290 & 82.4 \\
\hline & $>3$ months & 62 & 17.6 \\
\hline \multirow[t]{2}{*}{ ART adherence } & Good & 301 & 85.5 \\
\hline & $\begin{array}{l}\text { Ever had fair and } \\
\text { poor }\end{array}$ & 51 & 14.5 \\
\hline \multirow{2}{*}{$\begin{array}{l}\text { Months on care after } \\
\text { ART }\end{array}$} & $\leq 6$ month & 56 & 15.9 \\
\hline & $>6$ month & 296 & 84.1 \\
\hline
\end{tabular}

$A R T$ antiretroviral therapy, WHO World Health Organization

5.5 times (AHR $=5.5,95 \% \mathrm{CI} 1.5-20.6)$ higher risk of $\mathrm{TB}$ infection than their counterparts (Table 2).

\section{Discussion}

This study aimed to assess TB incidence rate and its predictors in children on ART. Accordingly, the overall TB incidence rate was 2.63 (95\% CI 1.9-3.7) per 100 personyears. This finding was comparable to that of a study conducted in south Ethiopia [31]. This might be due to similar socio-economic characteristics, HIV care settings, and HIV care guideline.

On the other hand, TB incidence rate of this study was higher than that of a study conducted in Latin America [16], UK and Ireland [32], and China [20]. This variation 


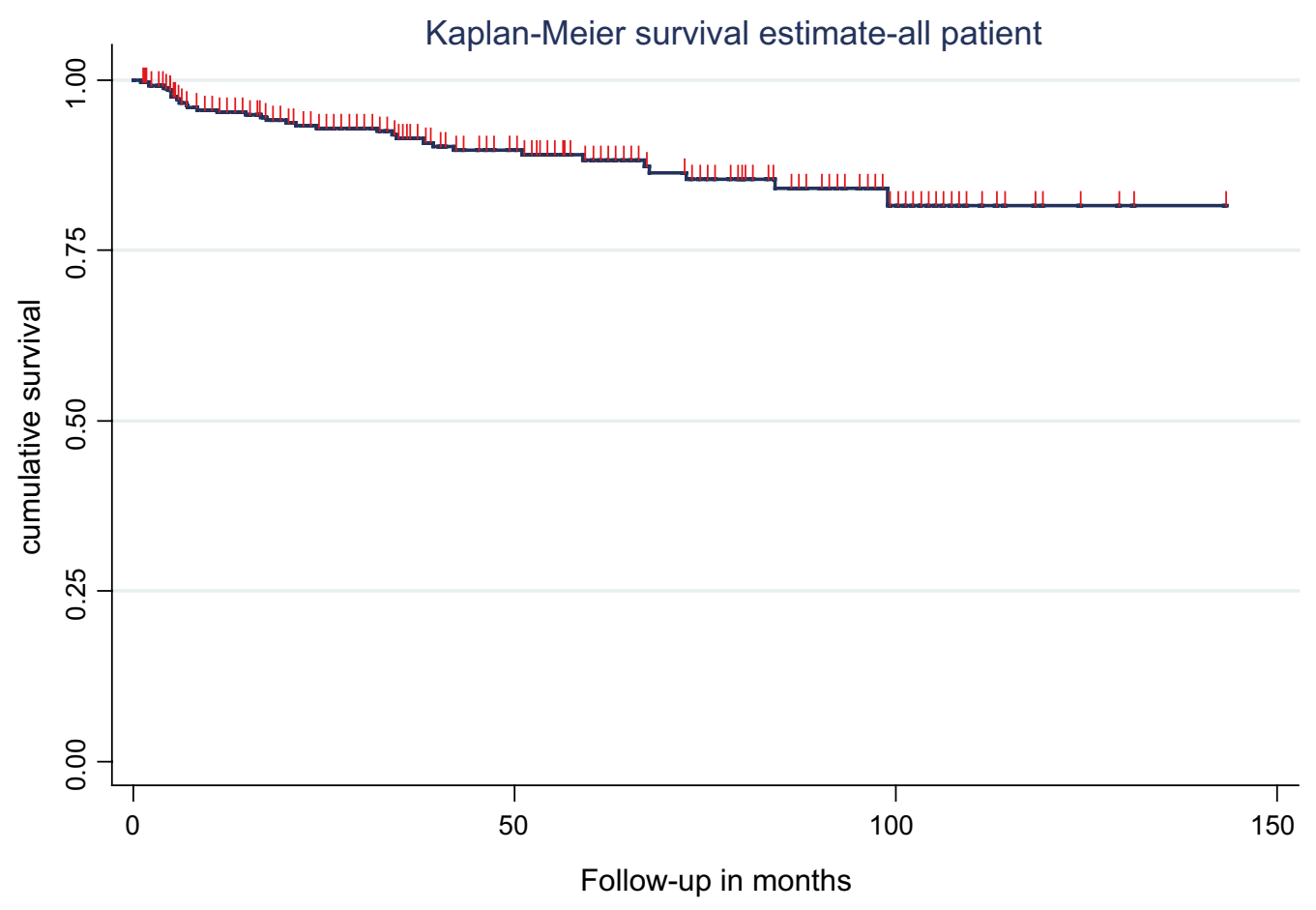

Survivor function $-\ldots$ Censored

Fig. 1 Kaplan-Meier estimate of TB-free probability in children on ART at Debre-Markos Referral Hospital, Northwest Ethiopia from March 2005 to April 2017

might be due to the fact that the incidence rate of $\mathrm{TB}$ was low in the general population of high-income countries. Besides, the presence of advanced technologies, implementation of early TB diagnosis and prevention strategies in developed countries play a significant role to reduce TB incidence [33]. Other possible reasons, like poverty, crowding, many family members, and poor housing conditions contribute to a higher TB incidence rate in Ethiopia.

In the current study, WHO clinical stage, level of ART adherence, late initiation of ART, and duration on ART were associated factors of TB incidence. This study showed that the incidence of TB was higher among WHO clinical stages 3 and 4 compared to 1 and 2. This finding was in agreement with those of studies done in Tanzania [24], China [20], UK, and Ireland [32]. The declining of immunity in advanced WHO clinical stages accelerates the progression of latent TB infection to active TB infection so that children presenting with advanced WHO clinical stages need to have close monitoring.

It is encouraging that early initiation of ART [34] to be one of the relevant strategies for the prevention of OIs, like TB. Initiation of ART early after confirmation of HIV infection even at higher CD4 cell count helps to reduce the occurrence of TB [35]. In our study, those children initiated ART lately were more likely to develop TB infection. Other studies in Tanzania [24] and Kenya [36] also revealed that the risk of TB infection was higher among children who started ART lately.

ART is continuing to prevent TB among HIV positive patients [37]. Having "fair" and "poor" adherence level to ART creates a suitable environment for viral replication and can facilitate the emergence of ART resistance, which could leads to an increased viral load, and a declining immunological status and opportunistic infections become prevalent as a result. This study established "fair" and "poor" ART adherence level was found to be a risk factor of TB incidence.

In the current study, children who took ART for less than or equal to 6 months were at higher risk of developing TB compared to those who took ART for more than 6 months. Similar studies conducted in Kenya [9, 38], Uganda and Zimbabwe [39], Tanzania [24], Cote D'Ivoire [40], and South Africa [21] were concordant with ours. A possible explanation was children might have had a nonsymptomatic TB at the time of ART initiation. Moreover, 
Table 2 Cox-proportional hazard analysis of predictors of TB incidence in children on ART at Debre-Markos Referral Hospital, Northwest Ethiopia from March 2005 to April 2017

\begin{tabular}{lll}
\hline Variables & Bivariable & Multivariable \\
${\mathrm{HR}(95 \% \mathrm{Cl})} \mathrm{HR}(95 \% \mathrm{Cl}) } }$
\end{tabular}

\section{Age}

$\begin{array}{lllll}\text { 0-5 year } & 0.860 & 1.1(0.4,3.1) & & \\ \text { 5-10 year } & 0.861 & 1.1(0.4,3.0) & \\ \text { 10-15 year } & & 1 & \\ \begin{array}{l}\text { Sex } \\ \text { Male }\end{array} & & 1 & \\ \text { Female } & 0.428 & 1.4(0.7,2.6) & & \\ \text { Residence } & & & & 1 \\ \text { Urban } & & 1 & & \\ \text { Rural } & 0.051 & 2.3(1.0,5.3) & 0.333 & 1.7(0.6,5.0)\end{array}$

Parent status

Both parents alive

Paternal/maternal orphan

Double orphan

WHO clinical stage

Stage 1 and 2

Stage 3 and 4

CD4 count

Below threshold

Above threshold

Hemoglobin

$<10 \mathrm{mg} / \mathrm{dl}$

$\geq 10 \mathrm{mg} / \mathrm{dl}$

Nutritional status

Underweight

Normal

Ever taking CPT

Yes

No

Ever taking IPT

Yes

No

Months on care before ART

\begin{tabular}{|c|c|c|c|c|}
\hline$\leq 3$ month & & 1 & & 1 \\
\hline$>3$ month & $<0.001$ & $12.6(6.2,25.7)$ & 0.006 & $4.0(1.5,10.6)^{*}$ \\
\hline \multicolumn{5}{|l|}{ ART adherence } \\
\hline Good & & 1 & & 1 \\
\hline $\begin{array}{l}\text { Ever had fair and } \\
\text { poor }\end{array}$ & $<0.001$ & $17.4(8.4,35.9)$ & 0.005 & $4.0(1.5,10.8)^{*}$ \\
\hline \multicolumn{5}{|c|}{ Months on care after ART } \\
\hline$\leq 6$ month & $<0.001$ & $13.1(5.2,33.1)$ & 0.011 & $5.5(1.5,20.6)^{*}$ \\
\hline$>6$ month & & 1 & & 1 \\
\hline
\end{tabular}

$H R$ hazard ratio, $\mathrm{Cl}$ confidence interval *independently significant at a 0.05 patients may come up with other severe co-OIs which might divert the attention of health professionals to control other OIs. Furthermore, patients who started ART might experience changes in clinical manifestations due to the unmasking of clinical signs and symptoms [41].

TB continues to be the public health agenda in Ethiopia. Therefore, prevention of TB through strengthening of TB diagnostic approaches and implementation of strong preventive strategies to children on ART has been suggested. Notably, newly emerging prophylaxis regimen in the prevention of TB [42] needs to be considered. More emphasis is required for the first 6 months after ART initiation. Parents and/or caregivers should be incorporated into HIV care settings to retain children on ART regimens. In Ethiopia, due to many reasons, children might not start ART soon after confirmation of HIV status. Initiation of early childhood diagnosis and screening in the community need more emphasis to identify them before advanced disease stages.

\section{Limitation of the study}

This study was retrospective follow-up and depends on medical records, which are not designed for research; the small numbers of children in some exposure categories; the reliance on clinical diagnosis for most children and the potential for misclassification that arises from this. TB incidence might be underestimated due to excluded of charts with incomplete data. Variables, like income, housing condition, caregiver, family size, and viral load were not investigated. This study took nearly a 12 -year period, during which there were likely several changes to clinical practice. The time-covariate variable was not handled because the data were collected at baseline.

\section{Abbreviations}

AIDS: Acquired Immunodeficiency Syndrome; AHR: adjusted hazard ratio; ART: highly active antiretroviral therapy; CD4: Cluster of Differentiation 4; Cl: confidence interval; CPT: cotrimoxazole prophylactic therapy; DRC: Democratic Republic of Congo; HIV: human immunodeficiency virus; IPT: isoniazid prophylactic therapy; Ol: opportunistic infection; TB: tuberculosis; UK: United Kingdom; WHO: World Health Organization.

\section{Authors' contributions}

AE worked on designing the study, training the data collectors, supervising the data collectors, interpreting the result, and preparing the manuscript. EHE and NT participated on designing the study, critically reviewing the study, interpreting the result, and preparing the manuscript. All authors have read and approved the manuscript.

\section{Acknowledgements}

The authors acknowledged University of Gondar for its financial support, Debre-Markos Referral Hospital, and data collectors.

\section{Competing interests}

The authors declare that they have no competing interests. 


\section{Availability of data and materials}

Data will be available upon request from the corresponding author.

\section{Consent to publication}

Not applicable.

\section{Ethical approval and consent to participate}

Ethical clearance was obtained from an Institutional review committee of the School of Nursing, College of Medicine and Health Sciences, University of Gondar.

\section{Funding}

Not applicable.

\section{Publisher's Note}

Springer Nature remains neutral with regard to jurisdictional claims in published maps and institutional affiliations.

Received: 25 August 2018 Accepted: 11 October 2018

Published online: 20 October 2018

\section{References}

1. Sharma S, Mohan A, Kadhiravan T. HIV-TB co-infection: epidemiology, diagnosis \& management. Indian J Med Res. 2005;121(4):550.

2. Daniel O, Adejumo O, Gidado M, Abdur-Razzaq H, Jaiyesimi E. HIV-TB co-infection in children: associated factors and access to HIV services in Lagos, Nigeria. Public Health Action. 2015;5(3):165-9.

3. Tsai K-S, Chang H-L, Chien S-T, Chen K-L, Chen K-H, Mai M-H, et al. Childhood tuberculosis: epidemiology, diagnosis, treatment, and vaccination. Pediatr Neonatol. 2013;54(5):295-302.

4. Seddon JA, Shingadia D. Epidemiology and disease burden of tuberculosis in children: a global perspective. Infect Drug Resist. 2014;7:153-65.

5. World Health Organization. Global tuberculosis report. Geneva: World Health Organization; 2016.

6. UNAID. Fact sheet: global HIV statistics. November 2016.

7. Rabie H, Frigati L, Hesseling AC, Garcia-Prats AJ. Tuberculosis: opportunities and challenges for the 90-90-90 targets in HIV-infected children. J Int AIDS Soc. 2015;18(Suppl 6):20236.

8. Uplekar M, Weil D, Lonnroth K, Jaramillo E, Lienhardt C, Dias HM, et al. WHO's new end TB strategy. Lancet. 2015;385(9979):1799-801.

9. Braitstein P, Nyandiko W, Vreeman R, Wools-Kaloustian K, Sang E, Musick $B$, et al. The clinical burden of tuberculosis among human immunodeficiency virus-infected children in Western Kenya and the impact of combination antiretroviral treatment. Pediatr Infect Dis J. 2009:28(7):626-32.

10. Frigati L, Kranzer K, Cotton M, Schaaf H, Lombard C, Zar H. The impact of isoniazid preventive therapy and antiretroviral therapy on tuberculosis in children infected with HIV in a high tuberculosis incidence setting. Thorax. 2011. https://doi.org/10.1136/thx.2010.156752.

11. Prasitsuebsai W, Kariminia A, Puthanakit T, Lumbiganon $P$, Hansudewechakul R, Law M, et al. Impact of antiretroviral therapy on opportunistic infections of HIV-infected children in the therapeutic research, education, and AIDS training Asia pediatric HIV observational database. Pediatr Infect Dis J. 2014;33(7):747-52.

12. Dodd PJ, Knight GM, Lawn SD, Corbett EL, White RG. Predicting the longterm impact of antiretroviral therapy scale-up on population incidence of tuberculosis. PLoS ONE. 2013;8(9):e75466.

13. Miranda A, Morgan M, Jamal L, Laserson K, Barreira D, Silva G, et al. Impact of antiretroviral therapy on the incidence of tuberculosis: the Brazilian experience, 1995-2001. PLoS ONE. 2007;2(9):e826.

14. Williams BG, Granich R, De Cock KM, Glaziou P, Sharma A, Dye C. Antiretroviral therapy for tuberculosis control in nine African countries. Proc Natl Acad Sci U S A. 2010;107(45):19485-9.

15. Forgacs P, Wengenack NL, Hall L, Zimmerman SK, Silverman ML, Roberts GD. Tuberculosis and trimethoprim-sulfamethoxazole. Antimicrob Agents Chemother. 2009;53(11):4789-93.

16. Alarcón JO, Freimanis-Hance L, Krauss M, Reyes MF, Cardoso CAA, MussiPinhata MM, et al. Opportunistic and other infections in HIV-infected children in Latin America compared to a similar cohort in the United States. AIDS Res Hum Retroviruses. 2012;28(3):282-8.

17. Zar HJ, Cotton MF, Strauss S, Karpakis J, Hussey G, Schaaf HS, et al. Effect of isoniazid prophylaxis on mortality and incidence of tuberculosis in children with HIV: randomized controlled trial. BMJ. 2007;334(7585):136.

18. Ayieko J, Abuogi L, Simchowitz B, Bukusi EA, Smith AH, Reingold A. Efficacy of isoniazid prophylactic therapy in prevention of tuberculosis in children: a meta-analysis. BMC Infect Dis. 2014;14(1):91.

19. $\mathrm{FMOH}$. Guidelines for the clinical and programmatic management of Tb, leprosy and Tb/HIV in Ethiopia. Addis Ababa: FMOH; 2012.

20. Mu W, Zhao Y, Sun X, Ma Y, Yu L, Liu X, et al. Incidence and associated factors of pulmonary tuberculosis in HIV-infected children after highly active antiretroviral therapy (HAART) in China: a retrospective study. AIDS Care. 2014:26(9):1127-35

21. Alana T. Brennan, Mhairi Maskew, Kate Schnippel, lan Sanne, Lawrence Long, Matt P. Fox. Risk factors associated with TB in children receiving ART in a South African multicenter HIV cohort. In: IAS-USA, editor. 927; March 3-6, 2014; Boston, Massachusetts. USA: Washington State Convention Center; 2014

22. Ciaranello A, Lu Z, Ayaya S, Losina E, Musick B, Vreeman R, et al. Incidence of WHO Stage 3 and 4 events, tuberculosis, and mortality in untreated, HIV-infected children enrolling in care before 1 year of age: an leDEA (International Epidemiologic Databases to Evaluate AIDS) East Africa regional analysis. Pediatr Infect Dis J. 2014;33(6):623.

23. Alemu YM, Andargie G, Gebeye E. High incidence of tuberculosis in the absence of isoniazid and cotrimoxazole preventive therapy in children living with HIV in northern Ethiopia: a retrospective follow-up study. PLoS ONE. 2016;11(4):e0152941.

24. Nan L, Manji KP, Spiegelman D, Aisa M, Mwiru RS, Enju L, et al. Incident tuberculosis and risk factors among HIV-infected children in Dar es Salaam, Tanzania. AIDS (London, England). 2013;27(8):1273.

25. Anígilájé EA, Aderibigbe SA, Adeoti AO, Nweke NO. Tuberculosis, before and after antiretroviral therapy among HIV-infected children in Nigeria: what are the risk factors? PLOS ONE. 2016;11(5):e0156177.

26. Rekha B, Swaminathan S. Childhood tuberculosis_-global epidemiology and the impact of HIV. Paediatr Respir Rev. 2007:8(2):99-106.

27. Central Statistical Agency. Ethiopian population and housing census. 2007

28. Federal HIV/AIDS Prevention and Control Office Ministry of Health (2007). Guidelines for paediatric HIV/AIDS care and treatment in Ethiopia. 2007.

29. World Health Organization. Patient monitoring guidelines for HIV care and antiretroviral therapy (ART). Geneva: World Health Organization; 2006.

30. World Health Organization. Antiretroviral therapy of HIV infection in infants and children in resource-limited settings: towards universal access. Recommendations for a public health approach. Geneva: World Health Organization; 2006.

31. Yirdaw KD, Jerene D, Gashu Z, Edginton M, Kumar AM, Letamo Y, et al Beneficial effect of isoniazid preventive therapy and antiretroviral therapy on the incidence of tuberculosis in people living with HIV in Ethiopia. PLOS ONE. 2014:9(8):e104557.

32. Turkova A, Chappell E, Judd A, Goodall RL, Welch SB, Foster C, et al. Prevalence, incidence, and associated risk factors of tuberculosis in children with HIV living in the UK and Ireland (CHIPS): a cohort study. Lancet HIV. 2015:2(12):e530-9.

33. Centers for disease control and prevention. Trends in tuberculosisUnited States. 2014.

34. Walters E, Duvenhage J, Draper HR, Hesseling AC, Van Wyk SS, Cotton $M F$, et al. Severe manifestations of extrapulmonary tuberculosis in HIVinfected children initiating antiretroviral therapy before 2 years of age. Arch Dis Child. 2014. https://doi.org/10.1136/archdischild-2013-305509.

35. Walensky RP, Wolf LL, Wood R, Fofana MO, Freedberg KA, Martinson NA, et al. When to start antiretroviral therapy in resource-limited settings. Ann Intern Med. 2009:151(3):157-66.

36. Abuogi L, Mwachari C, Leslie H, Shade S, Otieno J, Yienya N, et al. Impact of expanded antiretroviral use on incidence and prevalence of tuberculosis in children with HIV in Kenya. Int J Tuberc Lung Dis. 2013;17(10):1291-7.

37. Rangaka MX, Wilkinson RJ, Boulle A, Glynn JR, Fielding K, van Cutsem $\mathrm{G}$, et al. Isoniazid plus antiretroviral therapy to prevent 
tuberculosis: a randomised double-blind, placebo-controlled trial. Lancet. 2014;384(9944):682-90.

38. Crook AM, Turkova A, Musiime V, Bwakura-Dangarembizi M, BakeeraKitaka S, Nahirya-Ntege P, et al. Tuberculosis incidence is high in HIVinfected African children but is reduced by co-trimoxazole and time on antiretroviral therapy. BMC Med. 2016;14(1):50.

39. Martinson N, Moultrie H, Van Niekerk R, Barry G, Coovadia A, Cotton $M$, et al. HAART and risk of tuberculosis in HIV-infected South African children: a multi-site retrospective cohort. Int J Tuberc Lung Dis. 2009;13(7):862-7.
40. Auld A, Tuho M, Ekra K, Kouakou J, Shiraishi R, Adjorlolo-Johnson G, et al. Tuberculosis in human immunodeficiency virus-infected children starting antiretroviral therapy in Cote d'Ivoire. Int J Tuberc Lung Dis. 2014;18(4):381-7.

41. Lawn SD, Bekker L-G, Miller RF. Immune reconstitution disease associated with mycobacterial infections in HIV-infected individuals receiving antiretrovirals. Lancet Infect Dis. 2005;5(6):361-73.

42. Hakim J, Musiime V, Szubert AJ, Mallewa J, Siika A, Agutu C, et al. Enhanced prophylaxis plus antiretroviral therapy for advanced HIV infection in Africa. N Engl J Med. 2017;377(3):233-45.
Ready to submit your research? Choose BMC and benefit from:

- fast, convenient online submission

- thorough peer review by experienced researchers in your field

- rapid publication on acceptance

- support for research data, including large and complex data types

- gold Open Access which fosters wider collaboration and increased citations

- maximum visibility for your research: over 100M website views per year

At BMC, research is always in progress.

Learn more biomedcentral.com/submissions 